\title{
Rural-urban comparisons of dengue seroprevalence in Malaysia
}

\author{
Cheng Hoon Chew1, Yuan Liang Woon ${ }^{1} \mathbb{D}$, Faridah Amin², Tassha H. Adnan¹, Asmah Hani Abdul Wahab², \\ Zul Edzhar Ahmad², Mohd Adam Bujang', Abdul Muneer Abdul Hamid', Rahman Jamal', Wei Seng Chen ${ }^{4}$, \\ Chee Peng Hor ${ }^{5}$, Lena Yeap ${ }^{6}$, Ling Ping Hoo ${ }^{6}$, Pik Pin Goh ${ }^{1}$ and Teck Onn Lim*
}

\begin{abstract}
Background: Each year an estimated 390 million dengue infections occur worldwide. In Malaysia, dengue is a growing public health concern but estimate of its disease burden remains uncertain. We compared the urban-rural difference of dengue seroprevalence and determined age-specific dengue seroprevalence in Malaysia.

Methods: We undertook analysis on 11,821 subjects from six seroprevalence surveys conducted in Malaysia between 2001 and 2013, which composed of five urban and two rural series.

Results: Prevalence of dengue increased with age in both urban and rural locations in Malaysia, which exceeded $90 \%$ among those aged 70 years or beyond. The age-specific rates of the 5 urban surveys overlapped without clear separation among them, while prevalence was lower in younger subjects in rural series than in urban series, the trend reversed in older subjects. There were no differences in the seroprevalence by gender, ethnicity or region. Poisson regression model confirmed the prevalence have not changed in urban areas since 2001 but in rural areas, there was a significant positive time trend such that by year 2008, rural prevalence was as high as in urban areas.

Conclusion: Dengue seroprevalence has stabilized but persisted at a high level in urban areas since 2001, and is fast stabilizing in rural areas at the same high urban levels by 2008. The cumulative seroprevalence of dengue exceeds $90 \%$ by the age of 70 years, which translates into 16.5 million people or $55 \%$ of the total population in Malaysia, being infected by dengue by 2013.
\end{abstract}

Keywords: Dengue, Seroprevalence, Urban rural difference, Malaysia

\section{Background}

Dengue is an infection caused by the arbovirus that belongs to the genus Flavivirus (family Flaviviridae) and comprises four distinct, but closely related serotypes, DENV 1,2,3 and 4 [1]. Infection with any serotype confers lifelong immunity to that serotype, with partial and temporary cross immunity to other serotypes $[1,2]$. The dengue virus is an arthropod-borne virus that is primarily transmitted to humans by the Aedes aegypti and Aedes albopictus mosquitoes, a highly competent vector that is well adapted to human modified environment. It has spread extensively throughout the tropics and subtropics during the past 200 years through shipping trade

\footnotetext{
* Correspondence: limteckonn@gmail.com

${ }^{7}$ ClinResearch Pte Ltd, D7-3-1, Block D7, Pusat Perdagangan Dana 1, Jalan

PJU 1A/46, PJU 1A, 47301 Petaling Jaya, Selangor, Malaysia

Full list of author information is available at the end of the article
}

routes. The spread of the vector and hence the infection were amplified during the Second World War through the huge increase in movement of people and equipment aided by modern transportation [1,3-5].

Following the Second World War, rapid expansion and urbanization of the populations in South East Asia (SE Asia) and other tropical countries further intensified dengue transmission [3, 4]. Many dengue outbreaks have been documented since the 1950s in SE Asia and this has continued in ever larger cyclical epidemics [4]. By 2012, WHO reported that global incidence has increased 30 -fold in the past 50 years and estimated that some 50 - 100 million new infections occurred annually [6]. A recent estimate using the cartographic approach has pushed this number up to 390 million infections a year, more than three times WHO's estimate and Asia bore a disproportionate share of $70 \%$ of the global dengue 
burden [7]. In SE Asia, recent estimates have also shown a continuing increase in dengue incidence [8]. For example, in Malaysia where all 4 serotypes are circulating, the most recent estimate showed that incidence of dengue has risen 7 fold over the period between 2000 and 2010 [9]. These estimates of the increasing dengue incidence were based on data from dengue surveillance and cohort studies. Estimating incidence based on notification data is unreliable because of variable surveillance systems and healthcare infrastructures within and between countries. Besides, in contrast to infrequent sporadic infection, for a hyperendemic infection like dengue which had infected more than half of the population at any one time, and more than $90 \%$ of them over their lifetimes, notification of 35 million or more people over a decade or more in a typical mid-sized population like Malaysia poses significant practical challenges. The pre-existing passive dengue surveillance system is good for monitoring general trends, but inadequate to obtain a precise number of dengue cases as the total number of dengue cases is usually underreported in passive surveillance. For cohort studies, obtaining a sizable representative sample of both children and adults nationwide and following them over their lifetimes to ascertain infection risk is no less challenging especially in the developing countries where dengue is endemic. We believe that repeated seroprevalence surveys using low cost IgG enzyme-linked immunosorbant assays (ELISAs) is the most practical and likely most reliable method to estimate dengue incidence in endemic countries, though such surveys were uncommonly used in dengue epidemiologic research. A recent systematic review identified only 53 published seroprevalence surveys between 1980 and 2010 worldwide, and of these, only 30 surveys from 18 countries had usable IgG data and only one country had serial sero-survey data from multiple years [10]. Seroprevalence data provide estimates of the proportion of people in a population who have been previously infected by dengue. Series of seroprevalence data over several years also provides the basis for estimating disease incidence based on mathematical modelling of the relationship between incidence, prevalence and mortality. This approach has been widely used in HIV [11] and malaria [12] epidemiological research to estimate incidence and infection burden in endemic countries, but to our knowledge rarely used in the dengue research. This study aimed to compare the urban-rural difference of dengue seroprevalence and to determine age-specific dengue seroprevalence in Malaysia.

\section{Methods}

This study performed trend analysis on data extracted and compiled from published articles on dengue seroprevalence [13-15] and unpublished data collected from the sentinel surveillance conducted by National Public
Health Laboratory (NPHL) of the Ministry of Health $(\mathrm{MOH})$, Malaysia [16]. All patient data were analysed anonymously.

\section{Ethical approval}

This study was registered under National Medical Research Registry (NMRR, NMRR-15-961-26546) and was approved by Medical Research Ethics Committee, Ministry of Health.

\section{Study population}

Table 1 outlines the demographic characteristics for the 6 studies on dengue seroprevalence as mentioned above. All the studies included Malaysians from all age groups with exception of the Malaysian Cohort (TMC) study which included adults aged between 35 and 74 years. All studies were urban based except 2 series, Abu Bakar S. and Lim YA (ABL) which was entirely rural and TMC which has $40 \%$ of its sample from rural areas.

Study by Chen et al. [14] was based at a single urban primary care clinic where blood specimens of patients who attended for reasons unrelated to dengue or other febrile illnesses were collected [14]. The ABL was a rural school and community based study. TMC study was a nationwide, community based study of adults aged 3574 years living in urban and rural areas [17]. The NPHL conducts regular sentinel surveillance based at public health clinics located in urban areas only. In the surveillance, blood specimen of patients who attended the health clinics for reasons unrelated to dengue or other febrile illness from the age of 1 year old onward was collected (Amin F., personal communication). None of the studies included were hospital based, nor were blood specimens collected primarily for another purpose. However, none of the surveys were based on a random sample of households recruited from throughout the country. We obtained individual level records for all the studies except the ABL study.

We were unable to include data from two dengue vaccine trials conducted among Malaysian children [18, 19], because we have no access to the data and the studies employed a different serology method, which was serotype-specific plaque reduction neutralisation test $\left(\mathrm{PRNT}_{50}\right)$.

\section{Serological test}

The presence of dengue IgG antibodies in sera samples for all the seroprevalence studies was detected using the PanBio dengue IgG indirect ELISA [13-16].

\section{Statistical analysis}

\section{Age-specific seroprevalence rates of dengue}

The age-specific seroprevalence rate was constructed using the cubic spline method [20] by using Stata 
Table 1 Demographic characteristics of dengue seroprevalence studies in Malaysia

\begin{tabular}{|c|c|c|c|c|c|c|}
\hline Data source & ${ }^{\mathrm{a} C h e n ~ e t ~ a l . ~}$ & $\begin{array}{l}{ }^{\mathrm{b}} \mathrm{Abu} \text { Bakar S. and Lim YA } \\
\text { (ABL) }\end{array}$ & $\begin{array}{l}\text { 'The Malaysian Cohort study } \\
\text { (TMC) }\end{array}$ & ${ }^{\mathrm{d}} \mathrm{NPHL}$ & ${ }^{\mathrm{d}} \mathrm{NPHL}$ & ${ }^{d} \mathrm{NPHL}$ \\
\hline $\begin{array}{l}\text { Year of study } \\
\text { conducted }\end{array}$ & 2001 & 2007 & 2008 & 2011 & 2012 & 2013 \\
\hline Study setting & $\begin{array}{l}\text { Private primary } \\
\text { care clinic }\end{array}$ & $\begin{array}{l}\text { School and } \\
\text { Community }\end{array}$ & $\begin{array}{l}\text { Community based } \\
\text { nationwide study }\end{array}$ & $\begin{array}{l}\text { Public primary } \\
\text { care clinics }\end{array}$ & $\begin{array}{l}\text { Public primary } \\
\text { care clinics }\end{array}$ & $\begin{array}{l}\text { Public primary } \\
\text { care clinics }\end{array}$ \\
\hline Sample size & 85 & 1800 & 1000 & 3762 & 3911 & 1263 \\
\hline Mean age (in years) & 43 & 16 & 53 & 39 & 35 & 38 \\
\hline Age range (in years) & $5-71$ & $7-49$ & $35-74$ & $1-93$ & $1-88$ & $1-90$ \\
\hline \multicolumn{7}{|l|}{ Gender (\%) } \\
\hline Female & 46 & No data & 60 & 56 & 55 & 55 \\
\hline Male & 54 & No data & 40 & 44 & 45 & 45 \\
\hline \multicolumn{7}{|l|}{ Ethnicity (\%) } \\
\hline Malay & 8 & No data & 57 & 48 & 63 & 40 \\
\hline Chinese & 70 & No data & 37 & 27 & 15 & 25 \\
\hline Indian \& others & 22 & No data & 6 & 25 & 22 & 35 \\
\hline \multicolumn{7}{|l|}{ Geographical area (\%) } \\
\hline Peninsular Malaysia & 100 & 100 & 100 & 87 & 87 & 51 \\
\hline East Malaysia & 0 & 0 & 0 & 13 & 13 & 49 \\
\hline \multicolumn{7}{|l|}{ Location (\%) } \\
\hline Urban & 100 & 0 & 60 & 100 & 100 & 100 \\
\hline Rural & 0 & 100 & 40 & 0 & 0 & 0 \\
\hline
\end{tabular}

${ }^{\mathrm{a}}$ Suburban community in Puchong; ${ }^{\mathrm{b}}$ Aboriginal communities throughout the countries; ${ }^{\mathrm{c}}$ National cohort study throughout the country; ${ }^{\mathrm{d}} 7$ primary care clinics all located at city areas in different states of Selangor, Wilayah Persekutuan Kuala Lumpur, Perak, Kelantan, Johor and Sabah

Version 13. The method interpolated prevalence rates specified per five-year interval (or other irregular intervals) to one-year age groups.

\section{Poisson regression model}

Poisson regression model with random effect was used to determine time trend in dengue seroprevalence and age dependency in the risk of dengue infection stratified by urban or rural location. The outcome variable was count of seroconverted subjects while each study included was treated as random effect. The fixed effects were calendar year, age group and urban or rural location. The model equation is: $\log \left(\mathrm{P}_{\mathrm{i}}\right)=\log \left(\mathrm{N}_{\mathrm{i}}\right)+\beta_{0}+\beta_{1}$ Age $+\beta_{2}$ Year $+\beta_{3}$ Urban-Rural (UR) location $+\beta_{4}$ Age $_{\text {is }}{ }^{*}-$ Year $+\beta_{5}$ Age*UR $+\beta_{6}$ Year*i.UR $+\mu_{\mathrm{s}}+\varepsilon_{\mathrm{is}}$, where $\mathrm{P}_{\mathrm{i}}$ is the Prevalent count of dengue of a group $i$, which is cross-classified by levels of Age (8 levels) and UR location (2 levels). $\log (\mathrm{N})$ is the $\log$ transformed sample size of each Age-UR groups, $\beta_{0}$ is a constant, $\beta$ is a slope coefficient, $\mu_{\mathrm{s}}$ is the between survey error and $\varepsilon_{\text {is }}$ is the within group error.

Interactions were included in the Poisson regression model using age-by-calendar year, calendar year-bylocation and location-by-age. We hypothesised that: 1) when the age-by-calendar year interaction was positive and significant, seroprevalence of dengue increased with age and time; 2) when the calendar year-by-location interaction was positive and significant, seroprevalence of dengue increased over time and was dependent on urban-rural difference; 3) when the age-by-location interactions was positive and significant, seroprevalence of dengue increased with age of subjects and was dependent on urban-rural difference. Likelihood Ratio test for nested models or Bayesian Information Criterion for non-nested models was used to find the best fit for the data. The best fitting model is used to derive the pooled estimates of age-specific seroprevalence rates.

\section{Results}

Seroprevalence data were available for pooled sample of 11,821 subjects. The rate of seroprevalence in urban locations ranged between 61 and $92 \%$ and in rural locations ranged between 28 and $91 \%$. (Table 2).

The observed crude age-specific seroprevalence derived from the 6 studies were plotted as illustrated in Fig. 1 shows cubic spline smoothed estimates of agespecific seroprevalence for each study (TMC's rates below the age 35 and ABL's rates above age 49 were 
Table 2 Demographic characteristics and seroprevalence of dengue in Malaysia

\begin{tabular}{|c|c|c|c|c|c|c|}
\hline Study & Chen & $A B L$ & TMC & $\mathrm{NPHL}$ & $\mathrm{NPHL}$ & $\mathrm{NPHL}$ \\
\hline Year & 2001 & 2007 & 2008 & 2011 & 2012 & 2013 \\
\hline Sample size & 85 & 1800 & 1000 & 3762 & 3911 & 1263 \\
\hline Overall crude seroprevalence (\%) & 77 & 20 & 92 & 65 & 61 & 61 \\
\hline \multicolumn{7}{|l|}{ Gender (\%) } \\
\hline Male & 74 & No data & 94 & 66 & 64 & 60 \\
\hline Female & 79 & No data & 90 & 64 & 59 & 61 \\
\hline \multicolumn{7}{|l|}{ Ethnicity (\%) } \\
\hline Malay & 88 & No data & 92 & 56 & 59 & 55 \\
\hline Chinese & 71 & No data & 91 & 76 & 68 & 66 \\
\hline Indian and others & No data & No data & 92 & 68 & 60 & 64 \\
\hline \multicolumn{7}{|l|}{ Geographical area (\%) } \\
\hline Peninsular Malaysia & 77 & 20 & 94 & 65 & 60 & 57 \\
\hline East Malaysia & No data & No data & No data & 58 & 61 & 65 \\
\hline \multicolumn{7}{|l|}{ Location (\%) } \\
\hline Urban & 77 & No data & 92 & 65 & 61 & 61 \\
\hline Rural & No data & 20 & 91 & No data & No data & No data \\
\hline
\end{tabular}

extrapolated from available data in other age groups). The 5 urban studies have similar seroprevalence profiles by age. Seroprevalence rate of dengue increased with age in both urban and rural locations. By 65 years of age, at least $80 \%$ of Malaysian populations from both urban and rural locations were infected with dengue.

Using pooled data, there were no significant differences in the seroprevalence with regards to gender (Fig. 2), ethnicity (Fig. 3) and geographical areas (Fig. 4) across all age groups, as their $95 \% \mathrm{CI}$ overlapped with each other. The age-specific rate in urban areas was higher among the younger age of less than 40 years as compared to those from rural locations. The age-specific rate in urban areas was higher among the younger population aged of less than 40 years as compared to those from rural areas, whereas this trend is reversed by the age of 40 years, though the $95 \%$ confidence intervals overlapped at the higher age range (Fig. 5).

The Poisson regression model shows a statistically significant increase in dengue seroprevalence rates with increasing age (Table 3), higher among those living in urban locations as compared to rural locations (Fig. 6).

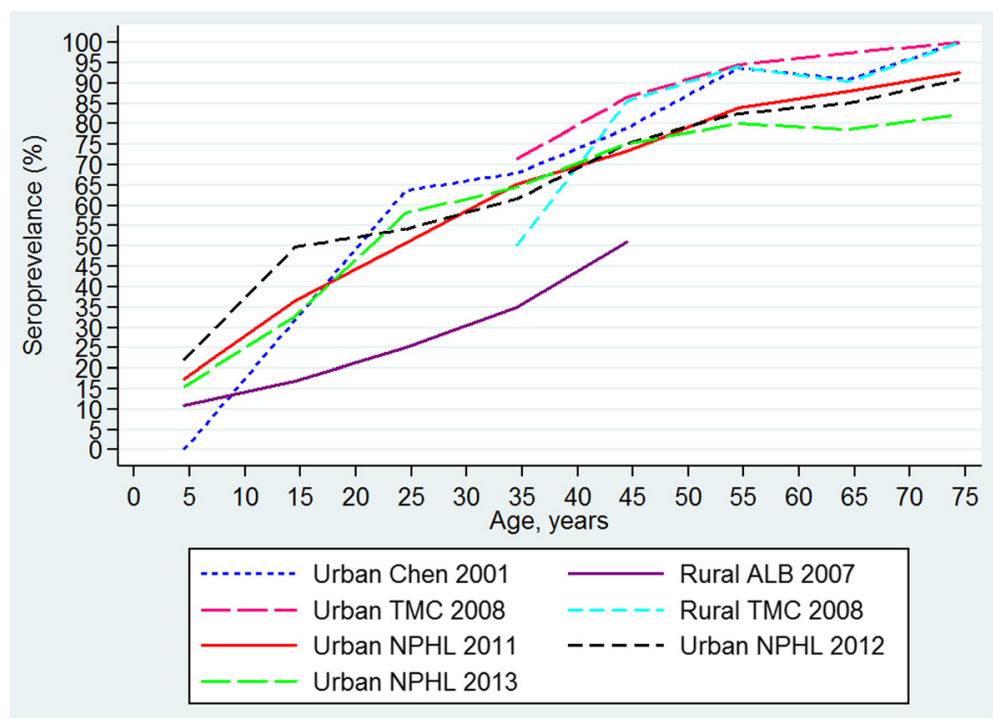

Fig. 1 Age-specific seroprevalence of dengue observed between 2000 and 2013 


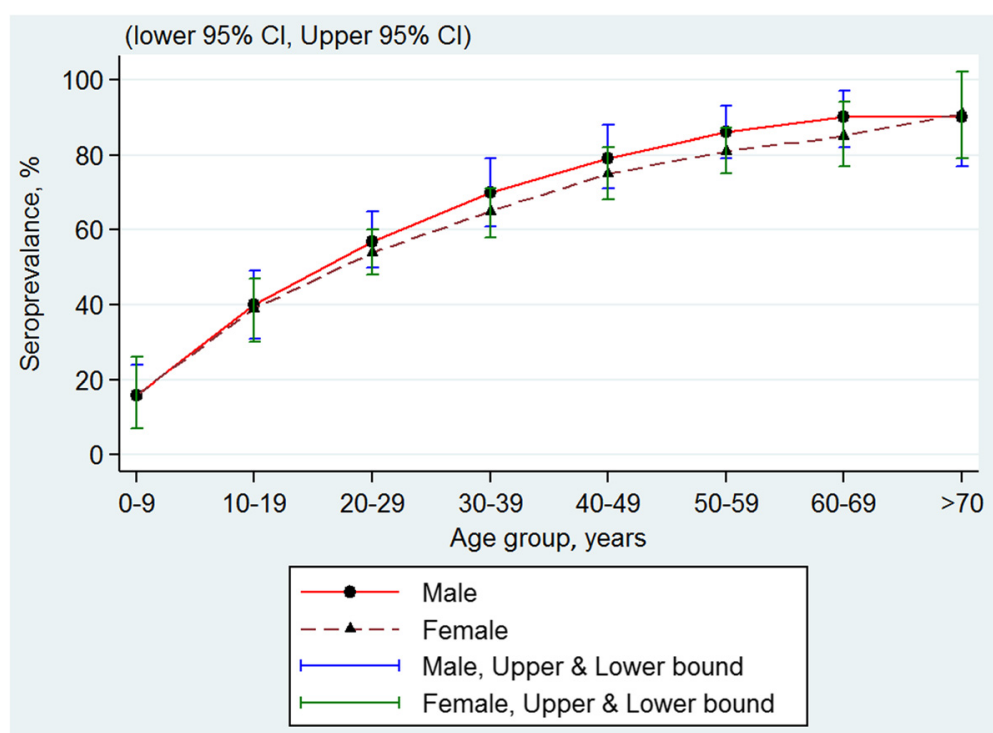

Fig. 2 Age-specific dengue seroprevalence estimates* by gender. Cubic spline smoothed and pooled across all surveys

When interactions were included in the model, there is a significant difference in the time trends of dengue seroprevalence by location (calendar year-bylocation interaction) (Table 3). While there has been no change in dengue prevalence at all in urban locations over time, dengue prevalence at rural locations increased over the years, showing a significant positive time trend. The age-by-location interaction is also significant suggesting that there is in addition an age dependent difference between urban and rural locations. The interaction between calendar year (time) and age is not significant (all $p$-values $>0.4$ ) indicating the age dependency in dengue seroprevalence has not changed over time.

Figure 6 shows the predicted age-specific dengue seroprevalence based on the results of the Poisson model (Table 3). In the absence of time trend (changes over calendar year), the data from predicted age-specific seroprevalence in urban locations for all years were pooled and presented in a single line. On the other hand, seroprevalence rates in rural areas show both positive time trend and age dependency. Thus, predicted age-specific seroprevalence was analysed and plotted for each calendar year. Only data for years 2001, 2004 and 2008 were

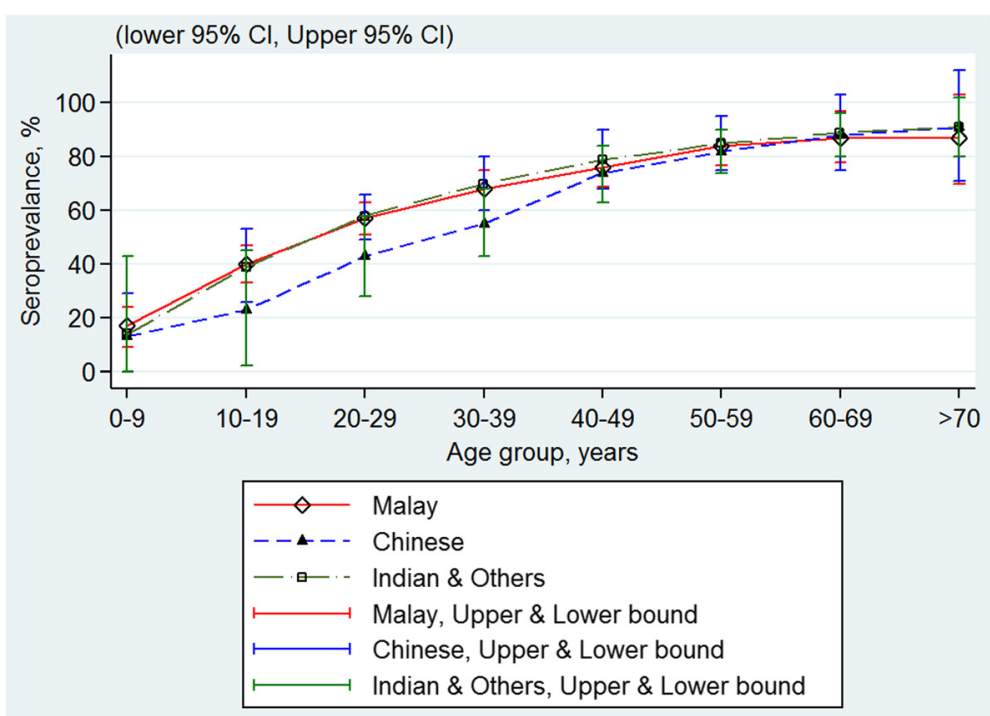

Fig. 3 Age-specific dengue seroprevalence estimate** by ethnicity. Cubic spline smoothed and pooled across all surveys 


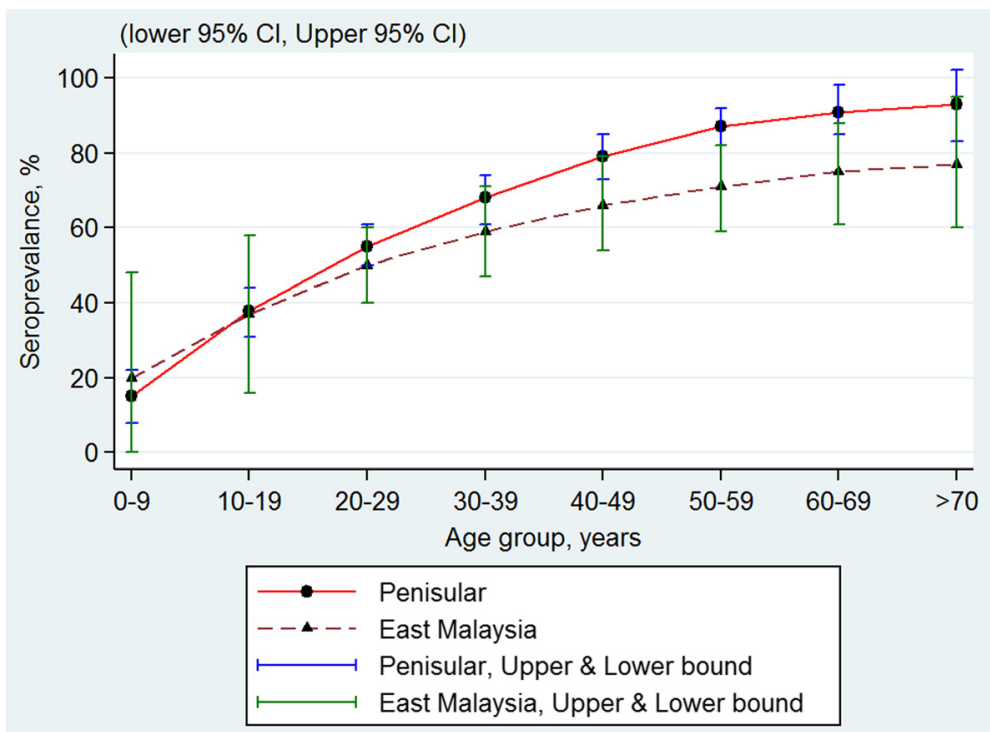

Fig. 4 Age-specific dengue seroprevalence estimates* by region. Cubic spline smoothed and pooled across all surveys

presented here to avoid crowding of Fig. 6 . The slopes of each of the 3 rural smoothened lines and the single urban line differ from one another indicating age dependency.

\section{Discussion}

Time trend in dengue seroprevalence

The increase in seroprevalence of dengue with age provides a measure of dengue infection in the past. The high seroprevalence observed since 2001 indicates a continuous high level of dengue virus exposure in our population. The age-specific dengue seroprevalence in age $x$ is a measure of cumulative prevalence of dengue at age $x$. However a single prevalence series cannot distinguish between no change in past dengue risk from time and/or agedependent change in risk of exposure. Our results, based on multiple series observed between 2001 and 2013, showed neither a time trend nor significant age dependency in dengue seroprevalence in urban area.

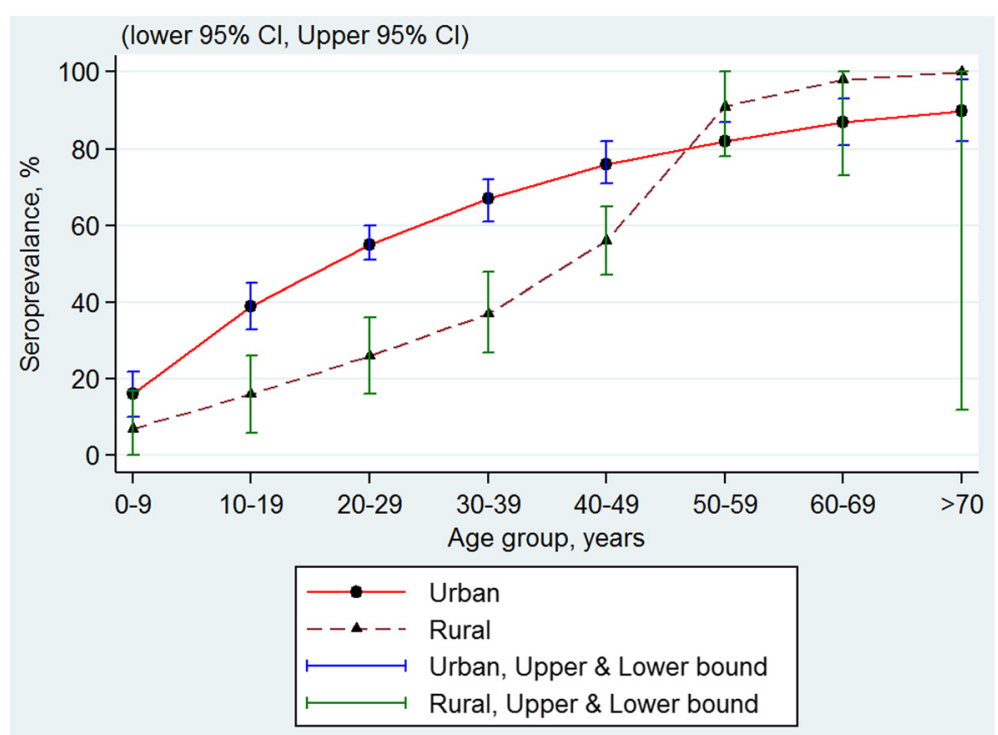

Fig. 5 Age-specific dengue seroprevalence estimates* by urban-rural location. Cubic spline smoothed and pooled across all surveys 
Table 3 Summary of regression coefficient (95\% Cl and p-values) from Poisson model of dengue seroprevalence in Malaysia between 2001 and 2013

\begin{tabular}{|c|c|c|c|}
\hline Variable & Coefficient & $95 \% \mathrm{Cl}$ & $p$-value \\
\hline \multicolumn{4}{|l|}{ Age group (in year) } \\
\hline $0-9$ & 0 & & - \\
\hline $10-19$ & $0 \cdot 88$ & $(0 \cdot 70,1 \cdot 07)$ & $<0 \cdot 0001$ \\
\hline $20-29$ & $1 \cdot 24$ & $(1 \cdot 07,1 \cdot 41)$ & $<0 \cdot 0001$ \\
\hline $30-39$ & $1 \cdot 42$ & $(1 \cdot 25,1 \cdot 60)$ & $<0 \cdot 0001$ \\
\hline $40-49$ & $1 \cdot 56$ & $(1 \cdot 39,1 \cdot 73)$ & $<0 \cdot 0001$ \\
\hline $50-59$ & $1 \cdot 63$ & $(1 \cdot 46,1 \cdot 80)$ & $<0 \cdot 0001$ \\
\hline $60-69$ & $1 \cdot 69$ & $(1 \cdot 51,1 \cdot 86)$ & $<0 \cdot 0001$ \\
\hline$>70$ & $1 \cdot 73$ & $(1 \cdot 55,1 \cdot 91)$ & $<0 \cdot 0001$ \\
\hline \multicolumn{4}{|l|}{ Location } \\
\hline Urban (referent) & 0 & - & - \\
\hline Rural & -600.91 & $(-1042,-160)$ & 0.0008 \\
\hline Calendar year & $-0 \cdot 0009$ & - & $<0 \cdot 0001$ \\
\hline \multicolumn{4}{|l|}{ Calendar year-by-Location interaction } \\
\hline All years at Urban location (referent) & 0 & - & - \\
\hline All years at Rural location & $0 \cdot 30$ & $(0 \cdot 08,0 \cdot 52)$ & $0 \cdot 0008$ \\
\hline \multicolumn{4}{|l|}{ Age-by-Location interaction } \\
\hline All ages at Urban location (referent) & 0 & - & - \\
\hline Age $0-9$ at Rural location & 0 & - & - \\
\hline Age $10-19$ at Rural location & $-0 \cdot 07$ & $(-0 \cdot 49,0 \cdot 35)$ & $0 \cdot 742$ \\
\hline Age $20-29$ at Rural location & $0 \cdot 06$ & $(-0 \cdot 41,0 \cdot 54)$ & $0 \cdot 799$ \\
\hline Age $30-39$ at Rural location & $0 \cdot 24$ & $(-0 \cdot 21,0 \cdot 68)$ & $0 \cdot 294$ \\
\hline Age $40-49$ at Rural location & $0 \cdot 45$ & $(0 \cdot 04,0 \cdot 86)$ & $0 \cdot 031$ \\
\hline Age $50-59$ at Rural location & $0 \cdot 58$ & $(0 \cdot 18,0 \cdot 98)$ & $0 \cdot 004$ \\
\hline Age $60-69$ at Rural location & $0 \cdot 67$ & $(0 \cdot 26,1 \cdot 07)$ & $0 \cdot 001$ \\
\hline Age $>70$ at Rural location & $0 \cdot 81$ & $(0 \cdot 40,1 \cdot 23)$ & $<0 \cdot 0001$ \\
\hline Calendar year-by-Age interaction & -0.003 to 0.05 & - & 0.06 to 0.9 \\
\hline
\end{tabular}

In other words, the dengue seroprevalence has been uniformly high in all age groups in urban areas in Malaysia since year 2001.

\section{Urban-rural difference in dengue seroprevalence}

Dengue is a highly transmissible urban disease on account of its mosquito vector, Aedes aegypti, which is well adapted to urban human environments [21]. The risk differential between urban and rural areas reported here is expected, especially in the younger age groups. Malaysia GDP per capita has increased 2.7 fold from USD 4,000 to USD 11,000 between 2001 and 2014 [22]. Besides, the urban population in Malaysia has increased from $62 \%$ of total population in 2000 to $71 \%$ in 2010 [23]. This rapid economic growth in the past 15 years and the associated increasing urbanization, as well as increasing population mixing enabled by the modern transportation network in the country all might have contributed to increasing homogeneity in dengue risk over time between urban and rural areas and in all age groups. Between 2001 and 2008, as shown in this study, the prevalence of dengue in rural areas was rising fast and converging towards the high levels observed in the urban population. We caution however that the prevalence estimates reported here for rural areas are based on only a small sample $(n=2200$ out of total sample of 11,821 subjects) from 2 sero-surveys and may be unduly sensitive to the limited data, as compared to 5 serosurveys for urban areas. To our knowledge, 30 serosurveys were conducted in 18 countries worldwide over the past 3 decades [10], but none of them reported on urban-rural differences to allow us to compare our results. We acknowledge that if another much larger survey had been conducted in the past in this or other country, it may not necessary show any difference between urban and rural locations. 


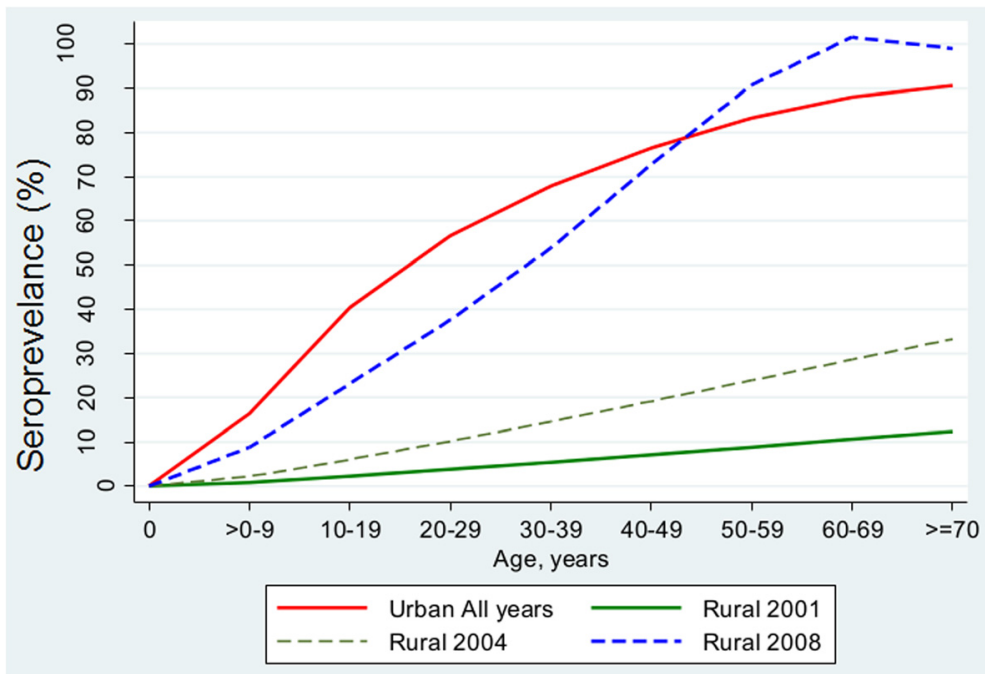

Fig. 6 Predicted age-specific dengue seroprevalence rate using Poisson regression model by urban-rural locations

This study has excluded data from two dengue vaccine trials which had included Malaysian children on account of the use of serotype-specific PRNT $_{50}$ test $[18,19]$. These trials have reported a very high baseline seroprevalence rate of $68 \%$ among the participating children aged $2-14$, which is much higher than the $35 \%$ rate in urban children by age 14 reported in this study. This is likely due to the use of highly sensitive $\mathrm{PRNT}_{50}$ test in these trials. Hence, the use of the less sensitive ELISA IgG test in the six sero-surveys included in this study has led us to underestimate the dengue seroprevalence. The actual seroprevalence in Malaysia was likely to be higher than the already very high level reported here.

\section{Dengue notification, healthcare utilization and disease severity}

There has been undoubtedly an increase in dengue notification in the past 15 years [24]. The number notified reached an all-time high of 108, 698 cases in 2014 (http:// idengue.remotesensing.gov.my/idengue/index.php). This has been widely interpreted as reflecting an underlying increasing trend in dengue incidence $[8,9]$ but our finding of a stable but high infection risk since 2001 is not compatible with this interpretation. Similarly the apparent age shift in dengue notification rates [25], widely interpreted as showing a shift in the risk of dengue to older age groups, is not compatible with our finding of uniform risk across all age groups in urban areas. We hypothesize that this paradoxical phenomenon of increasing notification and yet unchanging risk since 2001 is better explained by increasing healthcare utilization for dengue illness. In 2014, dengue was the top reason for hospitalization accounting for $14 \%$ of hospital admissions, and top 23rd reason for visits to primary care clinics in Malaysia [26]. Besides the increasing availability and wider distribution of health services, this may be partly driven by increasing number of symptomatic and severe cases especially in the older age groups, in contrast to the past observation that severe disease is predominantly seen in pediatric population [27]. This age shift in disease severity in turn may be related to the high persistent background dengue risk in this population leading to higher risk of secondary infections with prolonged exposure, which correlates with disease severity.

\section{Estimation of dengue incidence}

The demonstration of absence of time trend and age dependency in dengue risk in urban locations provides the justification for using a single pooled age-specific seroprevalence rates to estimate the age-specific incidence of dengue in urban population in Malaysia. For rural population however, age- and year-specific estimates will be required for the purpose. This is the subject of an ongoing work to estimate the incidence of dengue, incidence of dengue notification and hospitalization, as well as excess mortality associated with dengue illness.

\section{Conclusions}

The increasing incidence of dengue, often occurring in cyclical epidemics, has been well documented and it is a major public health concern in Malaysia. The trend analysis reported here showed that the risk of dengue has stabilized but persisted at a high level in urban areas since 2001, and is fast stabilizing in rural areas at the same high urban levels by year 2008. In the Malaysian population, the prevalence of infection is conservatively estimated to exceed $90 \%$ by the age of 70 years. This 
translates into 16.5 million people, or $55 \%$ of total Malaysian population, who have previously been infected by dengue by 2013.

\section{Acknowledgement}

The authors would like to acknowledge the authors of published articles and National Public Health Laboratory for sharing their raw data, Ms Teo Jau Shya and Dr. Neoh Hui-Min for their contributions and the Director General of Health for the permission to publish the article. The authors would also like to acknowledge the support from Malaysia Public Health Division in this project.

\section{Funding}

This study was funded by own institutional fee.

\section{Availability of Data and Materials}

Data are obtained from published articles on denque seroprevalence in Malaysia and unpublished data collected from the sentinel surveillance conducted by National Public Health Laboratory (NPHL) of the Ministry of Health $(\mathrm{MOH})$, Malaysia. In which, the authors of published articles may be contacted at drwschen@gmail.com and rahmanj@ppukm.ukm.edu.my; and the author of unpublished article may be contacted at drfaridah_ma@moh.gov.my.

\section{Authors' contribution}

CHC, YLW, CPH, PPG and TOL conceived and designed the study, as well as contributed to the writing of manuscript. ARAJ, WSC, AHAW, ZEA participated in design of the study and contributed the study materials. FA contributed study materials and participated in manuscript writing. THA, MAHB, AMAH, LY, LPH performed statistical analysis. All authors read and approved the final manuscript.

\section{Competing interest}

The authors declare that they have no competing interest.

\section{Consent for Publication}

Not applicable, as all data were anonymized in this study, no personal data presented.

\section{Ethics Approval and Consent to Participate}

This study was registered under National Medical Research Registry (NMRR, NMRR-15-961-26546) and was approved by Medical Research Ethics Committee, Ministry of Health Malaysia.

\section{Author details}

${ }^{1}$ Clinical Research Centre, c/o Third Floor, Dermatology Block, Hospital Kuala Lumpur, Jalan Pahang, 50586 Kuala Lumpur, Malaysia. ${ }^{2}$ National Public Health Laboratory, Lot 1853, Kg. Melayu, 47000, Sungai Buloh, Selangor, Kuala Lumpur, Malaysia. ${ }^{3}$ UKM Medical Molecular Biology Institute, UKM Medical Centre, Jalan Yaacob Latiff, Bandar Tun Razak, 56000, Cheras, Kuala Lumpur, Malaysia. ${ }^{4}$ Klinik Alam Medic, 41, Jalan Perdana 3/4, Taman Puchong Perdana, 47100, Puchong, Selangor, Kuala Lumpur, Malaysia. ${ }^{5}$ Kepala Batas Hospital, Jalan Bertam 2, 13200 Kepala Batas, Penang, Malaysia. ${ }^{6}$ Stats Consulting Pte Ltd, D7-3-1, Block D7, Pusat Perdagangan Dana 1, Jalan PJU 1A/46, PJU 1A, 47301 Petaling Jaya, Selangor, Malaysia. ${ }^{7}$ ClinResearch Pte Ltd, D7-3-1, Block D7, Pusat Perdagangan Dana 1, Jalan PJU 1A/46, PJU 1A, 47301 Petaling Jaya, Selangor, Malaysia.

Received: 8 March 2016 Accepted: 12 August 2016

Published online: 18 August 2016

\section{References}

1. Murray NE, Quam MB, Wilder-Smith A. Epidemiology of dengue: past, present and future prospects. Clin Epidemiol. 2013;5:299-309.

2. Wilder-Smith A, Ooi EE, Vasudevan SG, Gubler DJ. Update on dengue: epidemiology, virus evolution, antiviral drugs, and vaccine development. Curr Infect Dis Rep. 2010;12(3):157-64.

3. Gubler DJ. Dengue, Urbanization and Globalization: The Unholy Trinity of the 21(st) Century. Trop Med Health. 2011;39(4 Suppl):3-11.
4. Ooi EE, Gubler DJ. Dengue in Southeast Asia: epidemiological characteristics and strategic challenges in disease prevention. Cad Saude Publica. 2009;25 Suppl 1:S115-24.

5. Wilder-Smith A, Gubler DJ. Geographic expansion of dengue: the impact of international travel. Med Clin North Am. 2008;92(6):1377-90. x.

6. WHO. Global strategy for dengue prevention and control 2012-2020. Geneva, Switzerland: World Health Organization; 2012.

7. Bhatt S, Gething PW, Brady OJ, Messina JP, Farlow AW, Moyes CL, Drake JM, Brownstein JS, Hoen AG, Sankoh O, et al. The global distribution and burden of dengue. Nature. 2013;496(7446):504-7.

8. Arima Y, Matsui T. Epidemiologic update of dengue in the Western Pacific Region, 2010. Western Pac Surveill Response J. 2011;2(2):4-8.

9. Mia MS, Begum RA, Er AC, Abidin RD, Pereira JJ. Trends of dengue infections in Malaysia, 2000-2010. Asian Pac J Trop Med. 2013;6(6):462-6.

10. Imai N, Dorigatti I, Cauchemez S, Ferguson NM. Estimating dengue transmission intensity from sero-prevalence surveys in multiple countries. PLoS Negl Trop Dis. 2015;9(4), e0003719.

11. Hallett TB. Estimating the HIV incidence rate: recent and future developments. Curr Opin HIV AIDS. 2011;6(2):102-7.

12. Anders $\mathrm{KL}$, Hay SI. Lessons from malaria control to help meet the rising challenge of dengue. Lancet Infect Dis. 2012;12(12):977-84.

13. Abu Bakar S, Lim Y: Urbanization and the spread of dengue to rural populations in Malaysia (Abstract 11.095). In:International Society for Infectious Diseases - Neglected Tropical Diseases 2011 meeting: 2011. Boston: International Society for Infectious Diseases; 2011.

14. Chen WS, Wong $\mathrm{CH}$, Cillekens L. Dengue antibodies in a suburban community in Malaysia. Med J Malaysia. 2003;58(1):142-3.

15. Muhammad Azami NA, Salleh SA, Neoh HM, Syed Zakaria SZ, Jamal R. Dengue epidemic in Malaysia: Not a predominantly urban disease anymore. BMC Res Notes. 2011:4:216.

16. $\mathrm{MOH}$ Malaysia: National dengue sentinel surveillance programme (20112013). In. Edited by National Public Health Laboratory. Selangor; 2014.

17. Jamal R, Syed Zakaria SZ, Kamaruddin MA, Abd Jalal N, Ismail N, Mohd Kamil N, Abdullah N, Baharudin N, Hussin NH, Othman H, et al. Cohort Profile: The Malaysian Cohort (TMC) project: a prospective study of non-communicable diseases in a multi-ethnic population. Int J Epidemiol. 2015;44(2):423-31.

18. Hss AS, Koh MT, Tan KK, Chan LG, Zhou L, Bouckenooghe A, Crevat D, Hutagalung $Y$. Safety and immunogenicity of a tetravalent dengue vaccine in healthy children aged 2-11 years in Malaysia: a randomized, placebocontrolled, Phase III study. Vaccine. 2013;31(49):5814-21.

19. Capeding MR, Tran NH, Hadinegoro SR, Ismail HI, Chotpitayasunondh T, Chua MN, Luong CQ, Rusmil K, Wirawan DN, Nallusamy R, et al. Clinical efficacy and safety of a novel tetravalent dengue vaccine in healthy children in Asia: a phase 3, randomised, observer-masked, placebocontrolled trial. Lancet. 2014;384(9951):1358-65.

20. Wang Y: Smoothing Splines: Methods and Applications. Florida: Chapman \& Hall/ CRC Press; 2011.

21. Higa Y. Dengue Vectors and their Spatial Distribution. Trop Med Health. 2011;39(4 Suppl):17-27.

22. IMF: World Economic Outlook Database 2015. In.: International Monetary Fund; 2015. [Available at: https://www.imf.org/external/pubs/ft/weo/2015/ 01/weodata/index.aspx] (Accessed on 1 July 2015).

23. Department of Statistics. Press release: Report on characteristics of household 2010. Malaysia: Department of Statistics; 2014.

24. Mohd-Zaki AH, Brett J, Ismail E, L'Azou M. Epidemiology of dengue disease in Malaysia (2000-2012): a systematic literature review. PLoS Negl Trop Dis. 2014:8(11), e3159.

25. Bhatia R, Dash AP, Sunyoto T. Changing epidemiology of dengue in SouthEast Asia. WHO South-East Asia J Public Health. 2013;2(1):23-7.

26. CompuMed: Third Party Administrator Hospitalization Claims Transaction Database 2015. In. Kuala Lumpur: CompuMed; 2015.

27. Halstead SB. Dengue haemorrhagic fever-a public health problem and a field for research. Bull World Health Organ. 1980;58(1):1-21. 